\title{
Incredibly late thromboses in first generation drug eluting stents: a
}

\section{case series}

\author{
Zakir Shaik*1, Khaja S Mohammed ${ }^{2}$, Adnan Siddiqi2 ${ }^{2}$ Ilyas Mohammed ${ }^{1}$, \\ Timothy A Shapiro ${ }^{2}$ and Thomas P Phiambolis ${ }^{2}$
}

\author{
Address: ${ }^{1}$ Department of Internal Medicine, Main Line Health, Lankenau Hospital, 100 Lancaster Road, Wynnewood, Pennsylvania 19096, USA \\ and 2Division of Cardiology, Main Line Health, Lankenau Hospital, 100 Lancaster Road, Wynnewood, Pennsylvania 19096, USA \\ Email: Zakir Shaik* - shaikz@mlhs.org; Khaja S Mohammed - mohammeds@mlhs.org; Adnan Siddiqi - siddiqia@mlhs.org; \\ Ilyas Mohammed - mohammedi@mlhs.org; Timothy A Shapiro - shapirot@casep.com; Thomas P Phiambolis - phiambolist@casep.com \\ * Corresponding author
}

Published: 10 December 2009

Cases Journal 2009, 2:9303 doi:10.1186/1757-1626-2-9303

This article is available from: http://www.casesjournal.com/content/2/I/9303

(C) 2009 Shaik et al; licensee BioMed Central Ltd.

This is an Open Access article distributed under the terms of the Creative Commons Attribution License (http://creativecommons.org/licenses/by/2.0), which permits unrestricted use, distribution, and reproduction in any medium, provided the original work is properly cited.
Received: 10 November 2009

Accepted: 10 December 2009

\begin{abstract}
Background: The drug-eluting stents have decreased the incidence of instent restenosis compared to bare metal stents. But, the incidence of late and very late stent thrombosis has increased with the drug-eluting stents.
\end{abstract}

Case presentation: We are here, reporting three cases of incredibly late instent thrombosis, each one occurring after more than 50 months of drug-eluting stent placement.

Conclusion: The occurrence of stent thrombosis as late as 5 years has been reported in literature. This highlights the importance that there may be no limit to the time duration to the occurrence of very late stent thrombosis and dual antiplatelet therapy with aspirin and clopidogrel may have to be continued indefinitely in patients with drug-eluting stents.

\section{Background}

Though drug-eluting stents (DES) when compared with bare metal stents (BMS) have decreased the incidence of instent restenosis and subsequent target vessel revascularization, studies have highlighted the increased incidence of late and very late stent thromboses (VLST) with DES and their potential adverse clinical outcomes.

As per the standard definition from the Academic Research Consortium (ARC) stent thrombosis (ST) can be called acute, subacute, late and very late based on the timing [1]. An acute ST is defined as ST during percutaneous coronary intervention (PCI) or within the following 24 hours, subacute ST as between 1 and 30 days following PCI, late ST as between 1 month and 1 year following the
$\mathrm{PCI}$, and very late ST as more than one year following the PCI. The ARC has also standardized the definitions of a definite ST, possible ST and probable ST based on different criteria.

The longest reported interval between the implantation and thrombosis of a DES is about 67 months [2]. Here we report three cases of incredibly late ST occurring after 51 months (case 1), 58 months (case 2) and more than 50 months (case 3) from implantation, respectively. To our knowledge, the duration of 58 months in one of our cases represents one of the longest reported latencies from the placement to the occurrence of thrombosis described in the literature for the DES. 


\section{Case presentation Case report I}

A 60 year old Caucasian male presented with an acute coronary syndrome in October 2003. He had a history of hypertension, tobacco use, dyslipidemia and a family history of coronary artery disease. The coronary angiogram (CAG) showed $80 \%$ focal stenosis in the distal portion of the right coronary artery (RCA). The lesion was treated with a $2.5 \times 18 \mathrm{~mm}$ sirolimus eluting coronary stent (Cypher stent, Johnson \& Johnson, New Brunswick, New Jersey, USA) deployed at 12 atmospheres and post dilated at 14 atmospheres with a $2.75 \mathrm{~mm}$ non-compliant balloon. There was TIMI (Thrombolysis in myocardial infarction) grade 3 flow with no complications. He was discharged on aspirin and clopidogrel along with other standard medical regimen. While continuing to take the dual anti-platelet therapy he was readmitted on November 2004 with unstable angina. The CAG at this time showed a patent distal RCA stent but the posterior descending artery (PDA) was critically narrowed. The PDA lesion was treated with a $2.5 \times 13 \mathrm{~mm}$ sirolimus eluting stent (Cypher stent, Johnson \& Johnson, New Brunswick, New Jersey, USA) deployed at 11 atmospheres with satisfactory results and no complications. He was once again discharged on dual anti-platelet therapy.

In January 2008, the patient was readmitted with an acute inferior wall ST-elevation myocardial infarction (STEMI). He had continued on aspirin and clopidogrel since his

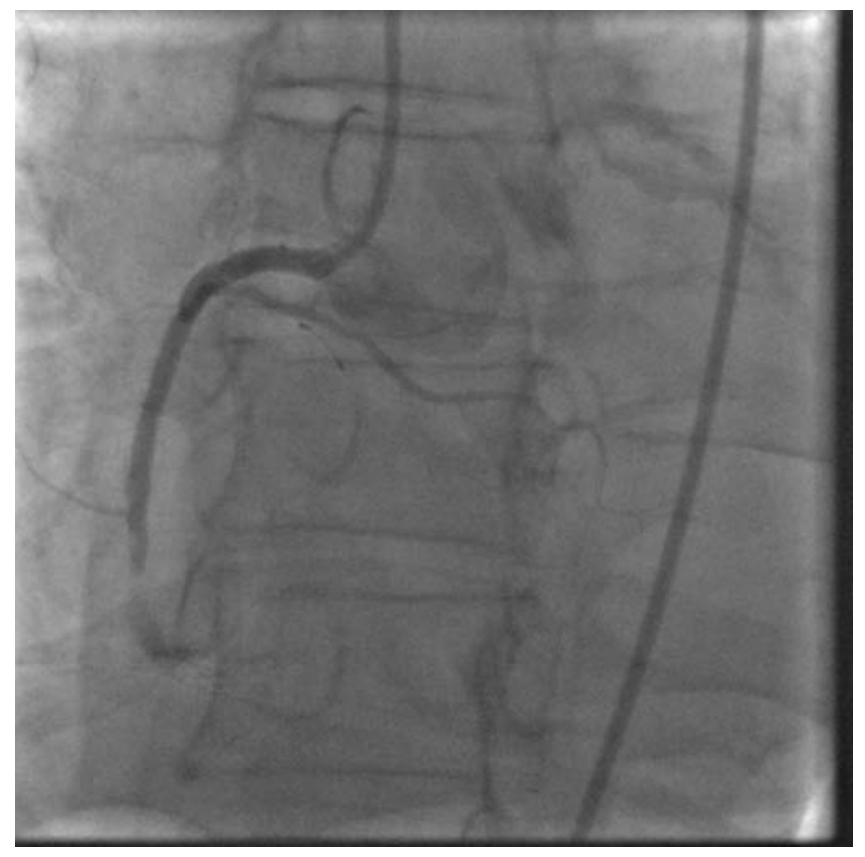

Figure I

Angiogram showing Thrombotic occlusion of DES in distal Right Coronary Artery. second stent was placed. His aspirin and clopidogrel were held 10 days prior to this episode for a dental procedure. On admission an emergent cardiac catheterization was performed which showed a thrombotic total occlusion of the previously placed DES in the distal RCA (Figure 1). The lesion was successfully dealt with using standard percutaneous intervention procedures (Figure 2). The postinterventional course was uneventful and the patient was discharged on dual anti-platelet therapy (DAT) WITH aspirin $325 \mathrm{mg}$ and clopidogrel $75 \mathrm{mg}$, to be continued indefinitely.

\section{Case report 2}

A 66 year old Caucasian male with the past history of hypertension and dyslipidemia underwent a cardiac catheterization in December 2003 because of exertional angina and a positive stress test. It showed critical disease with $90 \%$ stenoses of both the mid left anterior descending artery (LAD) and the mid RCA. The sirolimus eluting coronary stents (Cypher stent, Johnson \& Johnson, New Brunswick, New Jersey, USA) $2.75 \times 18 \mathrm{~mm}$ and $2.5 \times 18$ $\mathrm{mm}$ were deployed at 17 atmospheres in both the mid LAD and RCA lesions, respectively. Using a Quantum Maverick $3.0 \times 12 \mathrm{~mm}$ balloon, both were post-dilated at 18 atmospheres with a $0 \%$ residual stenosis, TIMI grade 3 flow and no peri-procedural complications. He was subsequently discharged on aspirin, clopidogrel and other standard medical regimen. The clopidogrel was stopped after the recommended treatment period of 3 months and after which he was continued on aspirin alone.

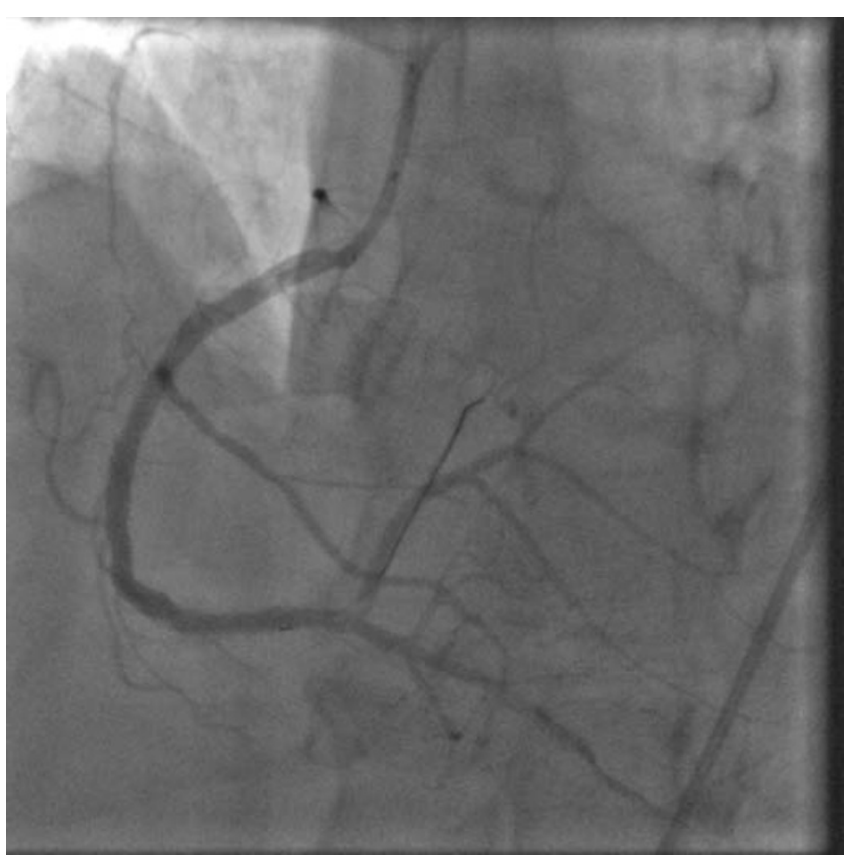

Figure 2

Angiogram of the distal Right Coronary Artery lesion after standard PCI. 
In October 2008, nearly 5 years post-stent placement, the patient was readmitted with an acute antero-septal ST-elevation MI. His aspirin was held about a week prior to this episode for a colonoscopy. An emergent left heart catheterization was performed which revealed a $100 \%$ occlusion of the mid LAD stent secondary to thrombosis and a $70 \%$ to $80 \%$ stenosis of the RCA within the stent secondary to likely thrombus (Figure 3 ). The patient was loaded with $600 \mathrm{mg}$ clopidogrel and abciximab infusion was started prior to the procedure. Both the lesions were dealt with successfully using standard procedural techniques with $0 \%$ residual stenosis and TIMI III flow (Figure 4 ). The 2D echocardiogram showed an akinetic left ventricular antero-apical region consistent with a LAD territory infarct and an ejection fraction of $35 \%$ to $40 \%$. The post-interventional course was uneventful and the patient was discharged on aspirin $325 \mathrm{mg}$ and clopidogrel $75 \mathrm{mg}$, to be taken indefinitely.

\section{Case report 3}

A 69 year old Caucasian male with a past history of hypertension, type 2 diabetes, dyslipidemia, coronary artery disease, history of coronary artery bypass graft to LAD, RCA and diagonal arteries in 1998, underwent an elective PCI with a paclitaxel-eluting coronary stent (Taxus Stent, Boston Scientific, Massachusetts, USA) to the proximal left circumflex artery in the early 2004 at another hospital. Our access to those records was limited. The patient was continued on DAT with aspirin and clopidogrel for nearly

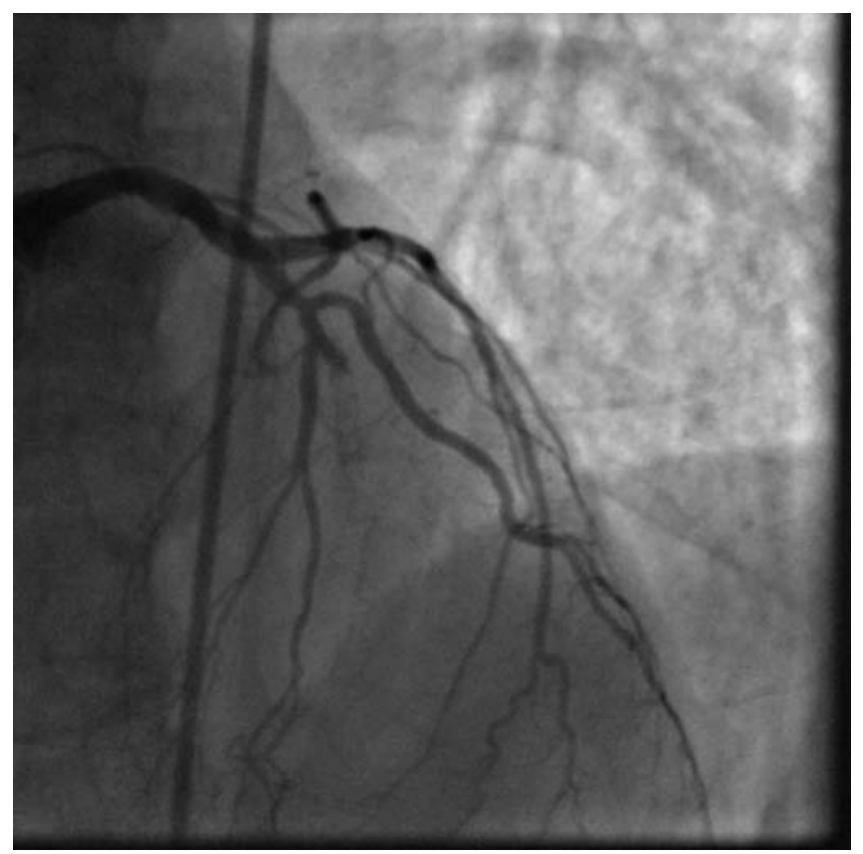

Figure 3

Angiogram showing complete thrombosis of DES in mid Left Anterior Descending artery.
6 months post-stent implantation following which clopidogrel was discontinued on account of extensive bruising.

More than 4 years later, in December 2008, the patient was admitted to our hospital with acute retrosternal chest pain associated with nausea and vomiting. The EKG showed sinus rhythm with an old left bundle branch block. The biomarkers were positive with a troponins I of 39.9 and a creatinine phosphokinase (CPK) of 1259 . He underwent an emergent cardiac catheterization that revealed patent bypass grafts but also showed a thrombus in the previously placed stent in the proximal left circumflex with a 99\% angiographic stenosis and TIMI 1 to 2 flow (Figure 5). The lesion was successfully treated with a percutaneous transluminal coronary angioplasty including mechanical thrombectomy using an X-Port catheter and using a Quantum Maverick $3.5 \times 18 \mathrm{~mm}$ balloon with restoration of TIMI 3 flow and no significant residual stenosis or evidence of distal embolization (Figure 6). The post-interventional course was uneventful and the patient was discharged on DAT.

\section{Conclusion}

The very late stent thrombosis (VLST) which occurs more than one year after stent implantation is a serious complication of first generation DES. The VLST has been reported to occur at rates varying between 0.2 to $0.7 \%$ of the DEStreated patients in various studies [3-7]. However, the incidence of VLST may be higher in real life than in clini-

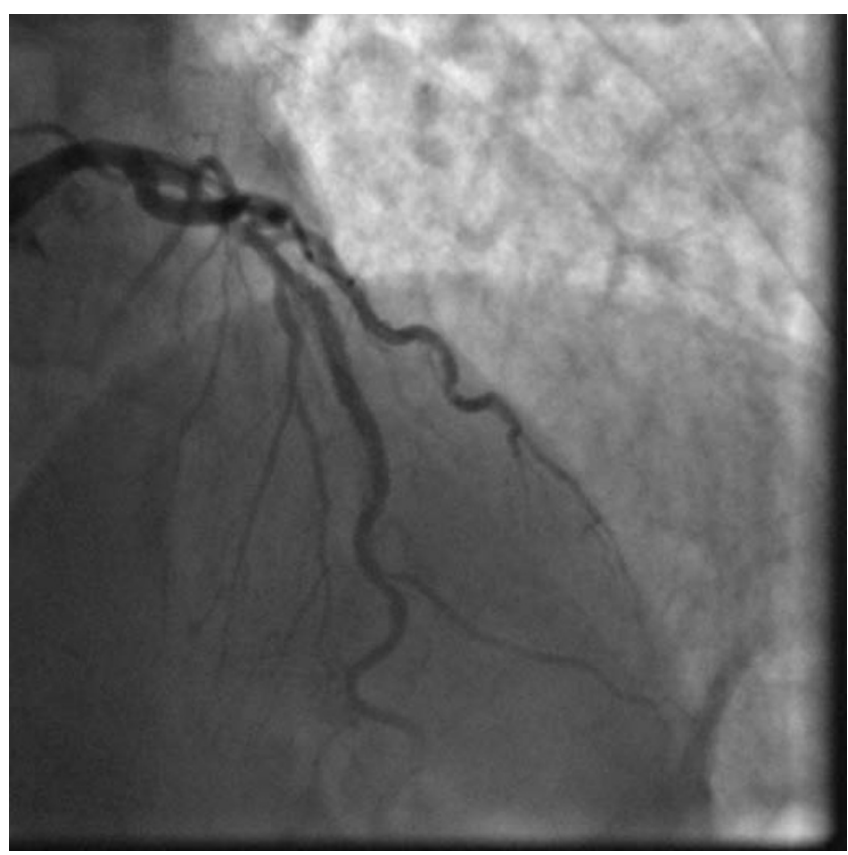

Figure 4

Angiogram of mid Left Anterior Descending Artery lesion after Standard PCI. 


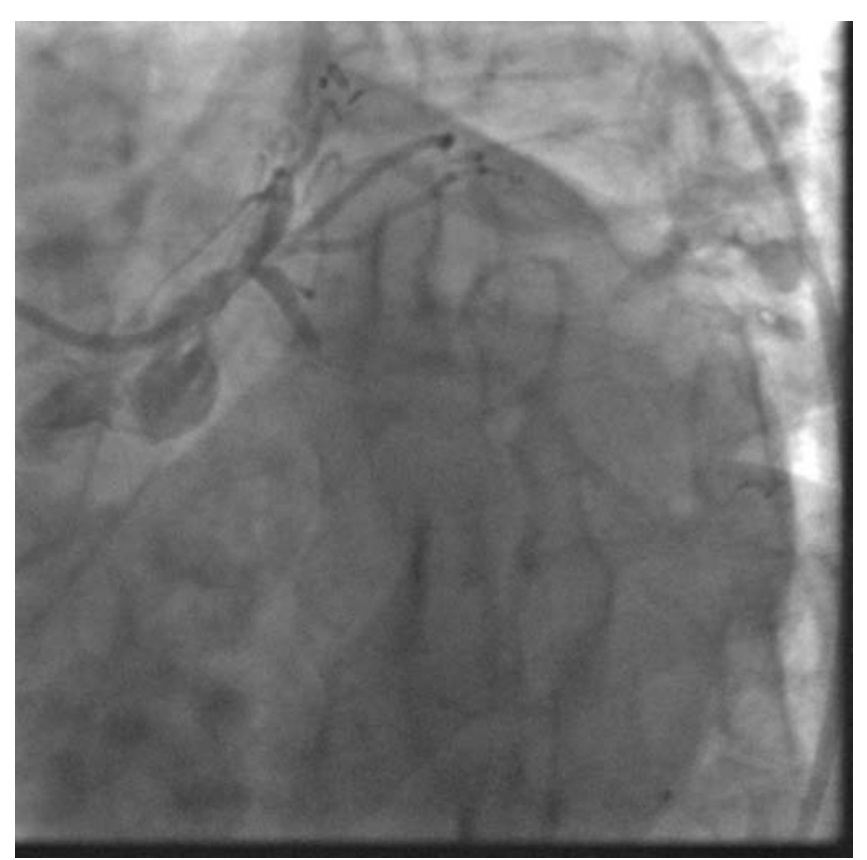

Figure 5

Angiogram showing thrombosis of DES in Left Circumflex artery.

cal trials because the real-life patients are potentially sicker, their lesions may be more complex, and follow up is longer.

The etiology of ST with DES is not yet completely elucidated. The discontinuation of thienopyridine therapy was shown to be a major determinant of ST within the first 6 months but discontinuation after 6 months did not predict the occurrence of ST in one study (hazard ratio 0.94) [8]. Several other determinants including renal failure, diabetes, low ejection fraction, in-stent restenosis, bifurcation lesions, type $\mathrm{C}$ lesions, and a trend for smaller-diameter stents have also been suggested to be the significant correlates of late stent thrombosis $[6,9]$. Besides these risk factors, delayed arterial healing post-stent implantation in combination with other risk factors like local hypersensitivity reaction, ostial location, mal-apposition or incomplete apposition of the stent and strut penetration into a necrotic lipid core have all been suggested to play a role in late stent thrombosis [10]. The cases of single DES thrombosis in patients with multiple intracoronary DES of the same duration suggest that the factors like incomplete stent apposition and/or, under-expansion and/or, significant residual reference-segment disease play a considerable role in the pathogenesis.

Pathologically, incomplete neointimal coverage leading to a delayed arterial healing in DES is probably an important explanation for the increased risk of thrombosis

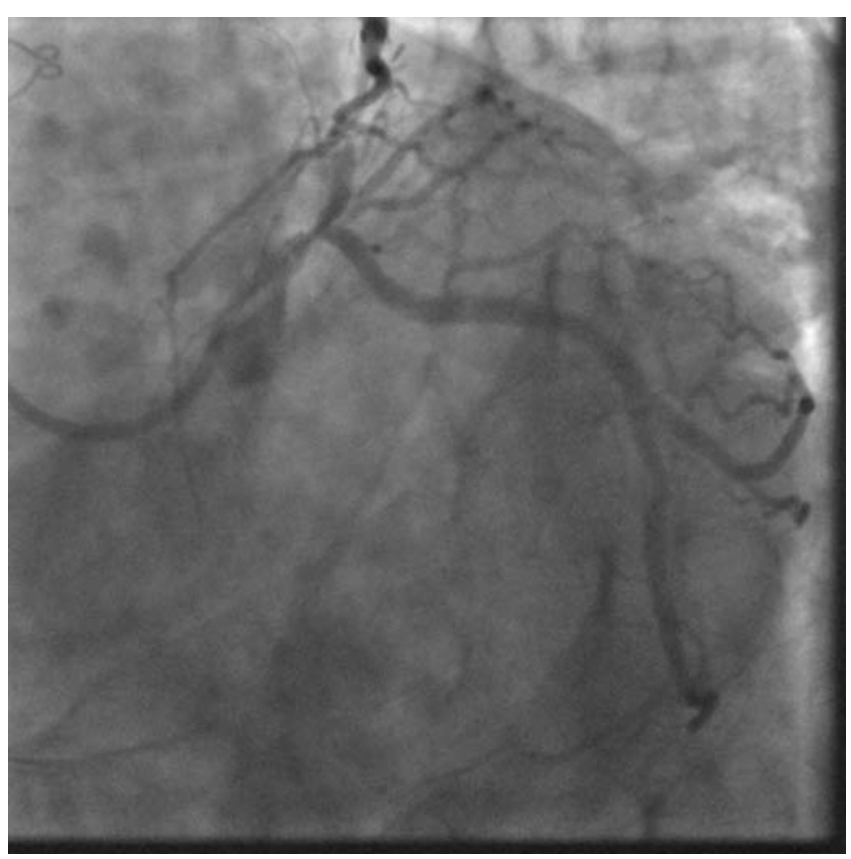

Figure 6

Angiogram of Left Circumflex after standard PCI.

(especially late or very late ST) in DES compared to BMS. A serial angioscopic follow up study comparing BMS and DES group of patients demonstrated that neointimal coverage was complete in all patients with BMS at ten months while the majority of patients with DES (sirolimus stents) had incomplete coverage at 21 months $(\mathrm{P}<0.05)$ [11]. It has also shown that the mural red thrombi were seen only in patients with DES and in those with incomplete neointimal coverage. From a registry study of 40 autopsies of DES (68 stents) by Joner et al, 23 DES cases of more than 30 days duration were compared with 25 matched autopsies of BMS implantation [10]. Out of those 23 patients with DES more than 30 days old, 14 had evidence of late stent thromboses and the delayed arterial healing was more pronounced in DES patients with late stent thrombosis than in those without stent thrombosis. In the same study, DES also showed poorer endothelialization $(55.8+/-26.5 \%)$ compared with BMS $(89.8+/-20.9, \mathrm{p}=$ $0.0001)$.

Ever since the approval of DES in 2003, cases of very late ST with increasing time interval between the implantation of DES and the thrombotic events are being reported. To our knowledge, the duration of 58 months in one of our cases represents one of the longest latency from implantation to thrombosis described in the literature for the DES. More and more reporting of such cases is extremely important to unravel the extent of the risk. These cases highlight the fact that there may be no limit to the time period for the definition of VLST, especially upon cessa- 
tion of antiplatelet therapy. The optimal duration of antiplatelet therapy (whether single or dual) remains questionable although the 2007 ACC/AHA/SCAI focused update of the $2005 \mathrm{PCI}$ guidelines recommended clopidogrel $75 \mathrm{mg}$ daily for at least 12 months in patients who receive a DES [12].

The guidelines might have to be revised recommending continuation of antiplatelet therapy for an unlimited period of time (even lifelong) for patients with a DES. The newer antiplatelet therapy like prasugrel (TRITON TIMI 38) also may affect treatment algorithm [13]. More importantly, before implanting a DES in any patient (either on-label or off-label use), strong considerations should be given to the degree of risk for restenosis and the patient's ability to comply with long-term dual antiplatelet therapy. DES implantation should be avoided if there is any doubt that the patient can comply with prolonged dual antiplatelet therapy and if the likelihood of future bleeding risk or necessity for surgical/invasive procedures is high.

Even if recommended to continue the antiplatelet therapy indefinitely in DES patients, the issue of incomplete neointimal coverage after a long term period with DES remains unresolved and little is known whether continuing the antiplatelet therapy itself will counterbalance the risks of having exposed stent struts, as cases of very late ST have also occurred while the DES patients were taking uninterrupted dual antiplatelet therapy [14]. However, 34 out of 36 cases of late ST in DES in one analysis were without clopidogrel at the time of the event [15]. It makes a stronger argument for continued long term DAT in such patients. Larger randomized studies with longer followups are needed to answer these questions with certainty. The new generation DES may behave differently and likely to have an improved safety profile. But, the data is very limited at this time and there is a need for large registries, clinical trials and head to head comparisons in a variety of situations before we conclusively prove they have greater efficacy and improved safety.

\section{Consent}

Written informed consent was obtained from each patient for publication of this case series and accompanying images. A copy of the written consent is available for review by the Editor-in-Chief of this journal.

\section{Competing interests}

The authors declare that they have no competing interests.

\section{Authors' contributions}

$\mathrm{ZS}, \mathrm{KM}$, and IM drafted and wrote the manuscript. AS, TS, and TP participated in the care of the patients. All authors read and approved the final manuscript.

\section{Acknowledgements}

We would like to thank all our patients who cooperated and consented for this manuscript.

\section{References}

I. Cutlip DE, Windecker S, Mehran R, Boam A, Cohen DJ, van Es GA, Steg PG, Morel MA, Mauri L, Vranckx P, McFadden E, Lansky A, Hamon M, Krucoff MW, Serruys PW: Clinical end points in coronary stent trials: a case for standardized definitions. Circulation 2007, I I 5:2344-235 I.

2. Layland J, Jellis C, Whitbourn R: Extremely late drug-eluting stent thrombosis: 2037 days after deployment. Cardiovasc Revasc Med 2009, I O(I):55-57.

3. Ong AT, McFadden EP, Regar E, de Jaegere PP, van Domburg RT, Serruys $\mathrm{PW}$ : Late angiographic stent thrombosis (LAST) events with drug-eluting stents. J Am Coll Cardiol 2005, 45( I 2):2088-2092.

4. Urban P, Gershlick AH, Guagliumi G, Guyon P, Lotan C, Schofer J, Seth A, Sousa JE, Wijns W, Berge C, Deme M, Stoll HP: Safety of coronary sirolimus-eluting stents in daily clinical practice: one-year follow-up of the e-Cypher registry. Circulation 2006 , I I3( I I): |434-I44I.

5. lakovou I, Schmidt T, Bonizzoni E, Ge L, Sangiorgi GM, Stankovic G, Airoldi F, Chieffo A, Montorfano M, Carlino M, Michev I, Corvaja N, Briguori C, Gerckens U, Grube E, Colombo A: Incidence, predictors, and outcome of thrombosis after successful implantation of drug-eluting stents. JAMA 2005, 293(I 7):2 I 26-2 I 30.

6. Stone GW, Moses JW, Ellis SG, Schofer J, Dawkins KD, Morice MC, Colombo A, Schampaert E, Grube E, Kirtane AJ, Cutlip DE, Fahy M, Pocock SJ, Mehran R, Leon MB: Safety and efficacy of sirolimusand paclitaxel-eluting coronary stents. N Engl J Med 2007, 356:998-1008.

7. Kastrati A, Mehilli J, Pache J, Kaiser C, Valgimigli M, Kelbaek H, Menichelli M, Sabate M, Suttorp MJ, Baumgart D, Seyfarth M, Pfisterer ME, Schomig A: Analysis of 14 trials comparing sirolimus-eluting stents with bare-metal stents. N Engl J Med 2007, 356: $1030-1039$.

8. Airoldi F, Colombo A, Morici N, Latib A, Cosgrave J, Buellesfeld L, Bonizzoni E, Carlino M, Gerckens U, Godino C, Melzi G, Michev I, Montorfano M, Sangiorgi GM, Qasim A, Chieffo A, Briguori C, Grube $E$ : Incidence and predictors of drug-eluting stent thrombosis during and after discontinuation of thienopyridine treatment. Circulation 2007, I I 6(7):745-54.

9. Kuchulakanti PK, Chu WW, Torguson R, Ohlmann P, Rha SW, Clavijo LC, Kim SW, Bui A, Gevorkian N, Xue Z, Smith K, Fournadjieva J, Suddath WO, Satler LF, Pichard AD, Kent KM: Waksman R-Correlates and long-term outcomes of angiographically proven stent thrombosis with sirolimus- and paclitaxel-eluting stents. Circulation 2006, I I3(8): I I08-I I I3.

10. Joner M, Finn AV, Farb A, Mont EK, Kolodgie FD, Ladich E, Kutys R, Skorija K, Gold HK, Virmani R: Pathology of drug-eluting stents in humans: delayed healing and late thrombotic risk. J Am Coll Cardiol 2006, 48(I): 193-202.

II. Awata M, Kotani J, Uematsu M, Morozumi T, Watanabe T, Onishi T, lida O, Sera F, Nanto S, Hori M, Nagata S: Serial angioscopic evidence of incomplete neointimal coverage after sirolimuseluting stent implantation: comparison with bare-metal stents. Circulation 2007, I I 6(8):910-916.

12. King SB, Smith SC Jr, Hirshfeld JW Jr, Jacobs AK, Morrison DA, Williams DO, 2005 WRITING COMMITTEE MEMBERS, Feldman TE, Kern MJ, O'Neill WW, Schaff HV, Whitlow PL, Adams CD, Anderson JL, Buller CE, Creager MA, Ettinger SM, Halperin JL, Hunt SA, Krumholz HM, Kushner FG, Lytle BW, Nishimura R, Page RL, Riegel B, Tarkington LG, Yancy CW: 2007 focused update of the ACC/ AHA/SCAI 2005 guideline update for percutaneous coronary intervention: a report of the American College of Cardiology/American Heart Association task force on practice guidelines: 2007 writing group to review new evidence and update the ACC/AHA/SCAI 2005 guideline update for percutaneous coronary intervention, writing onbehalf of the 2005 writing committee. Circulation 2008, I I 7:26 I.

13. Wiviott SD, Braunwald E, McCabe CH, Montalescot G, Ruzyllo W, Gottlieb S, Neumann FJ, Ardissino D, De Servi S, Murphy SA, Riesmeyer J, Weerakkody G, Gibson CM, Antman EM: Prasugrel versus 
clopidogrel in patients with acute coronary syndromes. $\mathrm{N}$ Engl J Med 2007, 357(20):200I-20I5.

14. Lim SY, Kim KS, Joo SJ, Jeong MH: Very late stent thrombosis after drug-eluting stent implantation in a patient without aspirin and clopidogrel resistance. J Korean Med Sci 2008, 23(3):556-559.

15. Artang R, Dieter RS: Analysis of 36 reported cases of late thrombosis in drug-eluting stents placed in coronary arteries. Am J Cardio 2007, 99(8): 1039-1043.

Publish with Bio Med Central and every scientist can read your work free of charge

"BioMed Central will be the most significant development for disseminating the results of biomedical research in our lifetime. " Sir Paul Nurse, Cancer Research UK

Your research papers will be:

- available free of charge to the entire biomedical community

- peer reviewed and published immediately upon acceptance

- cited in PubMed and archived on PubMed Central

- yours - you keep the copyright 